\title{
The Ontario New Graduate \\ Nursing Initiative: An Exploratory \\ Process Evaluation
}

\section{La Garantie d'emploi pour les diplômés en soins infirmiers de l'Ontario : une évaluation exploratoire des processus}

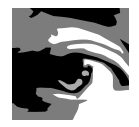

by JANICE BEATY, RN

Case Manager, Mississauga Halton CCAC Mississauga, ON

WENDY YOUNG, PHD

Canada Research Chair

Memorial University

St. John's, NL

MARLENE SLEPKOV, RN, BSCN

Interim Branch Manager - Niagara Site

VON Canada

Thorold, ON

WINSTON ISAAC, PHD

Director, Health Services Management

Ryerson University

Toronto, ON 
Janice Beaty et al.

SUE MATTHEWS, RN, DPH

Ontario Vice President, Operations

Chief of Practice and National Executive Director, Disease Management

VON Canada, Markham, ON

\begin{abstract}
Objective: To conduct an exploratory process evaluation of the Ontario Ministry of Health and Long-Term Care's (MOHLTC) New Graduate Nursing Initiative implemented by one home care agency.
\end{abstract}

Methods: Qualitative data were gathered online, stored electronically and then analyzed using an Affinity Diagram.

Results: Seven groupings of participants' comments were created: advertising and external information dissemination; orientation; internal dissemination; impact of the program; transition to the workforce; pay/benefits; and retention. Participants viewed many aspects of the program favourably but identified the following areas for improvement: comprehensibility of the Health Force Ontario website (advertising and external information); orientation of new graduates (orientation); and communication of information about the initiative to existing staff (internal dissemination).

Conclusions: This exploratory study points to both strengths and weaknesses of the New Graduate Nursing Initiative. Further study of the implementation of this policy is recommended.

\title{
Résumé
}

Objectif : Effectuer une évaluation exploratoire des processus de la Garantie d'emploi pour les diplômés en soins infirmiers - une initiative du ministère de la Santé et des Soins de longue durée de l'Ontario - mise en œuvre dans un établissement de soins à domicile.

Méthodologie : Des données qualitatives ont été recueillies en ligne et enregistrées numériquement, puis elles ont été analysées au moyen d'un diagramme d'affinités. Résultats : Les commentaires des participants ont été regroupés en sept catégories : recrutement et diffusion de l'information externe; orientation; diffusion interne; impact du programme; transition sur le marché du travail; salaire et avantages sociaux; et rétention. Les participants estiment que plusieurs aspects du programme sont favorables, mais indiquent les points suivants, qui pourraient être améliorés : la clarté du site Web Professions Santé Ontario (recrutement et information externe); l'orientation des nouveaux diplômés (orientation); et la communication au personnel en place de renseignements au sujet de l'initiative (diffusion interne).

Conclusions : Cette étude exploratoire indique à la fois les forces et les faiblesses de la Garantie d'emploi pour les diplômés en soins infirmiers de l'Ontario. Nous recom- 
mandons de mener des études plus poussées sur la mise en œuvre de cette politique.

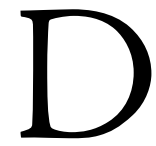

eCision-makers across Canada are developing and implementing

recruitment and retention policies to address the current and anticipated shortage of nurses (O'Brien-Pallas et al. 2003). In Ontario, for example, the Ministry of Health and Long-Term Care (MOHLTC) recently introduced the New Graduate Nursing Initiative, a comprehensive strategy for nursing workforce planning and management."The initiative ... seeks to ... promote the availability of permanent full time positions for new nurse graduates ... promote retention among Ontario's Nurse Graduates ... and facilitate recruitment to all sectors" (MOHLTC 2008). The Ministry of Health provides salaries for the first six months for newly recruited graduate nurses, both registered nurses (RNs) and registered practical nurses (RPNs). The new graduate nurse is paired with a mentor during this time frame to help make the transition from school to work.

If the new graduate nurse enters into a permanent full-time position after three months, but prior to six months, the employer may use the funds for other activities, such as backfilling of staff nurses, allowing nurses to intern into specialty positions. The remaining funds can also be used to assist internationally educated nurses to transition into the nursing workforce. If the new graduate is not in a full-time position after six months, the employer must commit to funding an additional six weeks of full-time employment for the new graduate, even if this is above complement.

To date there have been few evaluations of these policies (Shamian and El-Jardali 2007). Our exploratory process evaluation was designed to determine, from the perspective of participants within one home care organization (VON Canada), what works well and what does not work well with the implementation of the MOHLTC New Graduate Nursing Initiative. Ethics approval was received from VON Canada's Ethics Committee and Ryerson University.

\section{Methodology}

Design: An exploratory descriptive study

Participants: Of the 18 RNs and RPNs involved in the Initiative at VON Canada, six participated in our online study.

\section{Procedures}

One mini-focus group with four participants and two individual interviews were conducted online and recorded using methodology described by Gaiser (1997). All 
online statements by the participants were electronically saved in a readable file. Each participant was assigned a unique font colour, which provided a visual cue to ensure that all participants were contributing. Open-ended questions (see Appendix A) were distributed in advance to allow time for reflection. The questions focused on nurses' perceptions of the New Graduate Nursing Initiative. Nurses were asked to comment on what worked well, what did not work so well and how things could be improved.

The electronic file for the focus group and the files for the two individual interviews were created in real time and included all comments made by all participants. Each individual comment was printed onto a label and affixed to a "post-it" note. All notes were individually affixed to a large white board before the creation of the Affinity Diagram.

\section{Data analysis}

Four healthcare managers were instructed to create an Affinity Diagram. The Affinity Diagram "gathers large amounts of data and organizes them into groupings based on natural relationships" (Balanced Scorecard Institute 2007). The use of the Affinity Diagram to analyze qualitative data on nurses' perceptions has been used by Young and colleagues (2004). The instructions that were given to the healthcare managers were directly taken from webpage of the Balanced Scorecard Institute on the creation of the Affinity Diagram, titled "Affinity Diagram - How to Do It" (Balanced Scorecard Institute 2007). The managers were told to read the comments silently and move them one by one, placing together those that seemed to be most closely related. The managers were told that the cards could be moved among groups, and that the sorting would end when card movement ceased. The healthcare managers sorted cards for approximately two hours, and then together agreed on the common characteristics of the group. They put labels on each group and then displayed the relationships among the groups to create the Affinity Diagram (Balanced Scorecard Institute 2007).

\section{Results}

The healthcare managers arranged all comments into seven groups: (1) advertising and external information dissemination, (2) orientation, (3) internal dissemination, (4) impact of the program, (5) transition to the workforce, (6) pay/benefits and (7) retention. The relationships among these seven groups were visually displayed in the Affinity Diagram (Figure 1). The managers added a superheader, "Suggestions for Improvement," to show that the recent graduates had identified areas that were not working well in each of the seven groups. The interconnections are clear. At the top of the diagram is the theme of advertising and external information dissemination (group 1). The information distributed to students by academic institutions and by the government was viewed very favourably: "The school offered supportive information ... 
someone took the time to invest in our future. It made the process of signing up much easier." Participants said the Health Force Ontario website was well advertised, and some could easily access the job portal. Nevertheless, participants also commented that the website was not easy to understand.

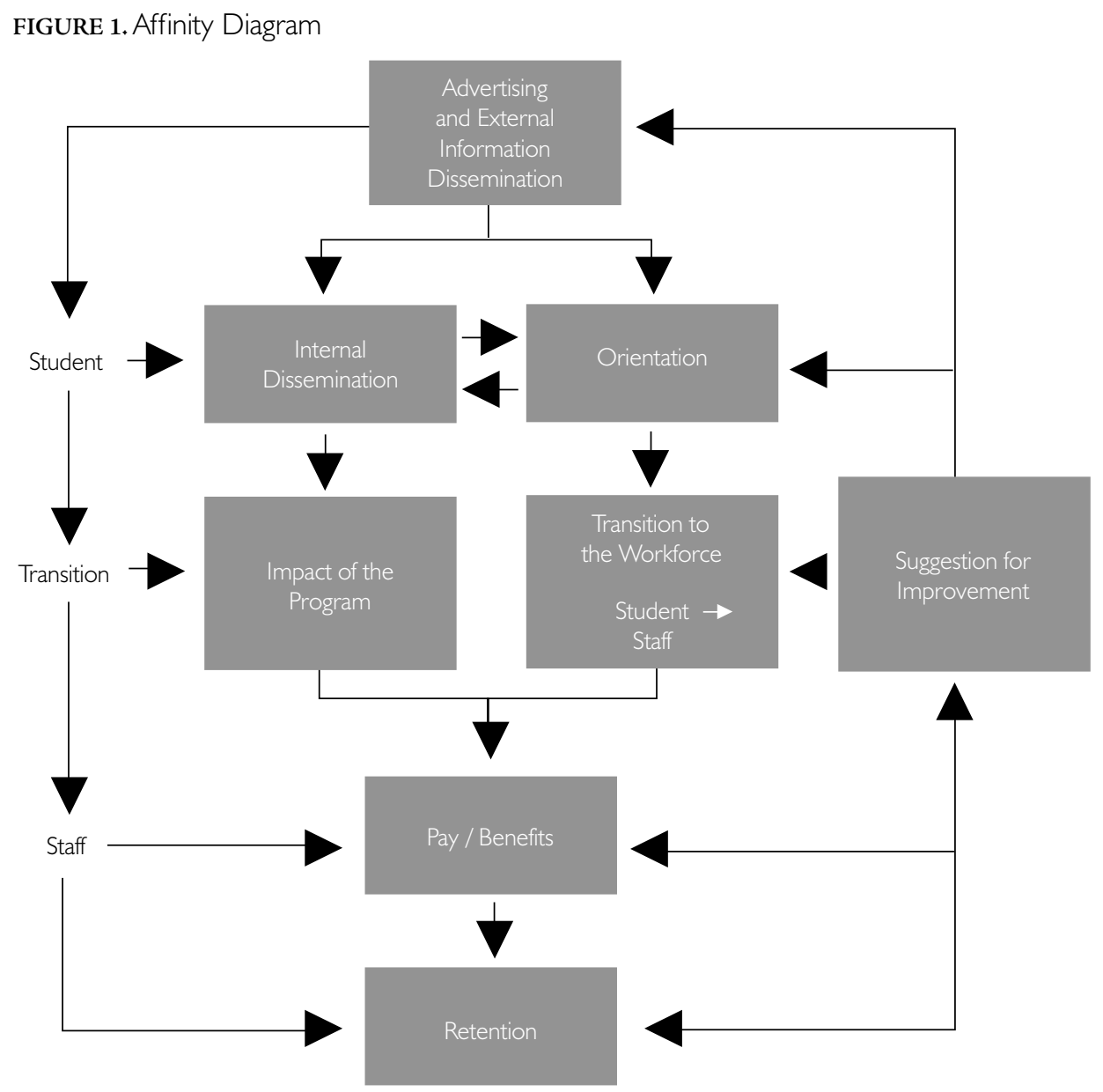

Advertising and external information dissemination is connected in the Affinity Diagram to orientation (group 2) and internal dissemination (group 3). The new graduates, once at the home care agency, received an orientation and began working with colleagues in the agency. Based on their experience, participants suggested that an orientation unique to the New Graduate Nursing Initiative be provided: "The orientation should be different. Many grads believed that most things were the same between grads and other employees, when they're not." ("Other employees" refers to experienced RNs and RPNs.) Other suggestions included more time for orientation and increased information on corporate policy and procedures, as well as on community nursing. 
Participants wanted more clarity on benefits, preceptorships, time frames and expectations. The participants also suggested improvements to the internal dissemination of information about the Initiative. In their opinion, some colleagues appeared to have received incomplete information because the colleagues wondered why the new graduate nurses were partnered with another nurse.

One can also see from the Affinity Diagram that once the new graduates got beyond the orientation phase, they were very enthusiastic about the impact of the program (group 4) and the transition to the workforce (group 5). Nurses were pleased to start working after graduating, and to have someone available to answer questions and provide on-the-job training. They were pleased with the "opportunity for additional learning, having a full-time job and guaranteed placement for six months." Participants appreciated activities that eased them into a staff position: "The support makes everything so much easier and less stressful. It was a great learning experience, and provided more peace of mind." With the support of a preceptor, one participant felt better prepared for independent practice: "My preceptor was and is great, she helped me with the idea of being on my own, allowing me to become more confident in my abilities to care for my patients."

The Affinity Diagram also highlighted the relationship of pay and benefits (group 6) to retention (group 7). Some participants commented that the New Graduate Nursing Initiative does not provide sufficient incentive to stay, given the pay differential, the extended workdays and the independent nature of community nursing. Nevertheless, the Initiative does help new graduates make the transition from school to employment."The program is a great incentive to keep nurses in Canada. Otherwise, I may have considered working in another country."

\section{Discussion}

Participants tended to view the MOHLTC's New Graduate Nursing Initiative, and VON's implementation of it, favourably. Participants appreciated how support provided by VON Canada eased their transition into becoming community nurses. In particular, the participants appreciated preceptors' dedication and support at this home care agency. Participants suggested that the Ministry should be applauded for recognizing the difficulties in nursing recruitment and retention. They stated that they appreciated the funding provided to address nursing recruitment and retention.

Participants also commented on what was not working well and identified areas for improvement, including a more specific orientation program. Compensation matters should be clearly identified during recruitment, and providing benefits from the time of hire would be a distinct advantage. Employees within the organization should know the program and how it is used. 


\section{Strengths and limitations}

This study has several strengths. First, it is the first evaluation of this new program. Second, it used online methods to collect qualitative data from geographically dispersed new graduates. Third, subjectivity in coding the verbatim quotes was addressed by the methods used to analyze the data. Experts coded the data until they reached consensus on themes and their interrelationships.

This study also has some limitations. Given its qualitative nature and the small sample size, we consider it a preliminary study. Because it was done at only one home care agency, the results may not be generalizable to other organizations.

\section{Recommendations for future study}

Our study can be a platform on which to build further studies. We recommend that a provincial survey be developed and administered in other organizations to obtain the perceptions of nurses about the New Graduate Nursing Initiative. Further, we recommend that additional focus groups be conducted on the Initiative after its second year of implementation.

\section{Conclusion}

This exploratory study suggests that the New Graduate Nursing Initiative may be an effective way to introduce nurses into practice. Nevertheless, further studies at other agencies are recommended. Further research and ongoing sharing of findings may contribute to providing an ample supply of qualified, dedicated nurses in the home care sector.

\section{ACKNOWLEDGEMENTS}

We would like to acknowledge Mr. Ralph Edward Beaty's contribution to this paper.

Correspondence may be directed to: Dr. Wendy Young, Canada Research Chair, Healthy Aging, Memorial University, St. John's, NL; A1C 5S7; tel.: 709-777-7098; e-mail: youngw@mun.ca.

\section{Appendix A: Focus Group Questions}

1. As a new nurse involved with this Initiative, what are your perceptions regarding the support that was provided to allow you to transition into practice within Community Health Nursing as a practising Registered Nurse or Registered Practical Nurse at VON Canada?

2. As a new nurse involved with this Initiative, how do you think VON Canada 
could enhance utilization of the New Graduate Initiative to support recruitment and retention of nurses within home care?

3. Tell me about your intentions in remaining employed with VON Canada as a result of this Initiative.

4. As a new nurse Involved with this initiative, what are your perceptions of what works well and what does not work well within the New Graduate Initiative at VON Canada?

5. As a new nurse involved with this Initiative, what are your impressions of how well staff embraced the program to support the transition from student to nurse at VON Canada?

\section{REFERENCES}

Abelson, J., S.T. Gold, C. Woodward, D. O'Connor and B. Hutchison. 2004. “Managing Under Managed Community Care: The Experiences of Clients, Providers and Managers in Ontario's Competitive Home Care Sector." Health Policy 68(3): 358-372.

Balanced Scorecard Institute. 2007 (October 8). Affinity Diagram. Retrieved March 26, 2009. $<$ http://www.balancedscorecard.org/files/affinity.pdf $>$.

Gaiser, T. 1997. “Conducting On-Line Focus Groups: A Methodological Discussion." Social Science Computer Review 15: 135-44.

Ontario Ministry of Health and Long-Term Care (MOHLTC). 2008. “Guidelines for Participation in the Nursing Graduate Guarantee for New Graduate Nurses." Retrieved March 26, 2009. <http://www.healthforceontario.ca/upload/en/work/2009_01_09_ngg_participation\%20g uidelines.pdf $>$.

O'Brien-Pallas, L., C. Alksnis and S. Wang. 2003. Bringing the Future into Focus: Projecting RN Retirement in Canada. Ottawa: Canadian Institute for Health Information.

Shamian, J. and F. El-Jardali. 2007. “Healthy Workplaces for Health Workers in Canada: Knowledge Transfer and Uptake in Policy and Practice." HealthcarePapers 7: 6-25.

Young, W., J. McShane, T. O'Connor, G. Rewa, S. Goodman, S. Jaglal, L. Cash and P.C. Coyte. 2004. "Registered Nurses' Experiences with an Evidence-Based Home Care Pathway for Myocardial Infarction Clients." Canadian Journal of Cardiovascular Nursing 14(3): 24-31. 